\title{
Development of Framework Linking Organizational Virtuousness and Pro-Social Rule Breaking: From the Perspective of Social Information Processing
}

\author{
Xian Zeng \\ School of Management, Jinan University, Guangzhou, China \\ Email: Zengxian179@163.com
}

How to cite this paper: Zeng, X. (2018) Development of Framework Linking Organizational Virtuousness and Pro-Social Rule Breaking: From the Perspective of Social Information Processing. Open Journal of Social Sciences, 6, 80-89. https://doi.org/10.4236/jss.2018.66008

Received: April 18, 2018

Accepted: May 29, 2018

Published: June 1, 2018

Copyright $\odot 2018$ by author and Scientific Research Publishing Inc. This work is licensed under the Creative Commons Attribution International License (CC BY 4.0).

http://creativecommons.org/licenses/by/4.0/

\begin{abstract}
Based on the theory of social information processing, this research develops a conceptual model linking organizational virtuousness perception and pro-social rule breaking. In this model, organizational virtuousness perception of employees positively affects the pro-social rule breaking via psychological empowerment; Proactive personality positively moderates the indirect effect of organizational virtuousness perception on pro-social rule breaking though psychological empowerment. The proposed conceptual framework reveals the functional mechanism of organizational virtuousness perception on pro-social rule breaking from cognitive perspective and discusses individual character's moderating role, which helps identify research gap and advance further knowledge development in organizational virtuousness.
\end{abstract}

\section{Keywords}

Organizational Virtuousness, Psychological Empowerment, Pro-Social Rule Breaking, Proactive Personality, Social Information Processing Theory

\section{Introduction}

Organizational virtuousness refers to an organization as a general ethical character [1]. Organizational virtuousness is of virtues as optimism, trust, compassion, integrity and tolerance, which will be embodied by individual or collective behavior, organizational structure, culture and processes within the organization [2]. In the past, many enterprise managers ignored the relationship between organizational virtuousness and enterprise economic results. However, in recent 
years, the moral bankruptcy and financial collapse of well-known companies in business have led the enterprise managers to review the value and significance of organizational virtuousness [3]. In 2011, the world's managers surveyed 1501 managers about why Chinese companies failed. $77.7 \%$ of those investigated thought that it was attributed to "a loss of business ethics", $74.1 \%$ of them considered that it resulted from "quick success without long-term development goals", and $62 \%$ of them deemed that it was because of "the lack of values". With the rise and development of business ethics research in the field of organizational research, many scholars have actively called for the research agenda of organizational virtuousness [4] [5] [6] [7].

As a positive organizational characteristic, the functional mechanism of organizational virtuousness has attracted the attention of scholars. Rego, for example, found that organizational virtuousness perception is partly responsible for organizing citizenship behavior through affective well-being [3]. The study of Tsachouridi and Nikandrou found that organizational virtuousness perception can promote the sense of pride and respect of employees, thus showing more spontaneous behaviors [8]. Hur et al. found that the positive affect triggered by organizational virtuousness perception can impact the organizational identity of employees, and then act on the task crafting of employees [9]. However, previous studies have mainly focused on the emotional mechanism of how organizational virtuousness perception affects employees' work behavior, while rather few studies have explored its effects from the cognitive perspective. According to the theory of cognitive affective personality system, in addition to the emotional factors within the individual, organizational context can also activate cognitive factors to influence individual behaviors [10]. Social information processing theory also emphasized the important role of individual cognition in social environment [11]. Therefore, it is necessary to explore the cognitive functional mechanism of organizational virtuousness fully uncover the "black box" of organizational virtuousness on employee's work outcomes. In addition, previous studies have not explored the moderating role of individual characteristics in the relationship between organizational virtuousness and employee behaviors. Individual behavior, however, is the interaction between environment and individual as a result. Many scholars think it necessary to include individual characteristics in organizational character research framework and to build a research framework structured by virtuous context, individual characteristics and individual performance, so as to gain a comprehensive insight into the organization mechanism of virtuous context [12] [13]. Cameron, the promoter of the organization virtuousness, also called on the future research to explore the functional mechanism of organizational virtuousness and to clarify the marginal conditions of its action [5].

In order to respond to the previous appeals, this paper, based on the theory of social information processing, focuses on the psychological cognitive process and the moderated role of the personality characteristics in the relationship be- 
tween organizational virtuousness and pro-social rule breaking. Pro-social rule breaking refers to employees' behaviors which intend to break formal rules, regulations and prohibitions of the organization for the sake of its own benefits [14]. Due to the fact that such kind of behavior is risky, employees tend to conduct a risk assessment of the behavior and thereafter do what is possible and reasonable. Social information processing theory points out that the social information within the organization situation provides a variety of clues that affect its attitudes and behaviors, and that the individual's behaviors depend on the individual's cognitive interpretation of such information [11]. As an ethical characteristic of the organization, organizational virtuousness is an important social cue in organizational context. The cognitive interpretation of these virtuous cues from the organization may affect the performance of their pro-social rule breaking. Psychological empowerment is a comprehensive recognition of the assessment of work environment, and the degree of psychological empowerment of individuals will affect the flexibility and innovation of their work behaviors [15].

Previous studies have shown that psychological empowerment is an important social information processing mechanism in the relationship between organizational context and behavioral outcomes of individuals [16]. Based on this, this study introduces the psychological empowerment as the social information processing process mediating the relationship between organizational virtuousness perception and pro-social rule breaking. Furthermore, individual social information processing is influenced by personality traits [17]. Studies have shown that personality differences will affect their attitudes and opinions towards pro-social rule breaking [18]. Some employees are more focused on the positive result of pro-social rule breaking and regard it as a chance to change the circumstance rather than a threat. For example, individuals with high proactive personality are better at discovering and seizing opportunities, tend to challenge the status quo and support innovative changes [19]. Therefore, this study will introduce the proactive personality into the research framework and discuss the moderating role of proactive personality.

To sum up, this article is attempting to develop an integrated approach to shed light on the functional mechanism of organizational virtuousness from cognitive perspective, and discuss the moderating role of individual characters. Specifically, based on literature review and social information processing theory, we provide a conceptual framework including organization virtuousness perception empowerment, proactive personality and pro-social rule breaking.

\section{Hypothesis Development}

\subsection{Organizational Virtuousness and Pro-Social Rule Breaking}

The theory of social information processing holds that the environment can provide clues to individuals, and the interpretation of these cues by individuals will influence their subsequent behavior [11]. However, individuals do not pay attention to all environmental cues. Individuals only interpret specific environ- 
mental information and determine the rationality of their behavior [11]. Pro-social rule breaking refers to violation of organization's policy, rules, regulations or prohibitions, and is likely to be punished by managers [16]. As a result, when employees are encountered such a circumstance as to whether they should risk to behave pro-social rule breaking for the sake of organization's benefits, they will be stuck in a decisional dilemma, Virtuous organizations call for individual or collective moral behaviors so as to pursue social values beyond their own interests [2], and pro-social rule breaking are aimed to help organizations or other stakeholders, which is a kind of virtuous behavior driven by altruistic motives [16]. On account of the fact that altruism of this very act is consistent with that of the organizational virtuousness, employees are more inclined to consider suchlike behavior is accepted by organizations, so as to reduce the negative assessment of implementation of this very behavior. In addition, the more ambiguous the behavioral decision is, the more obvious social information's impact will become [15]. Therefore, when employees are supposed to choose between sticking to the rules or being flexible to safeguard organization's interests, affected by the organizational virtuousness, they are more likely to violate the organization's rigid rules and regulations, and instead to safeguard the interests of the organization or their colleagues. Accordingly, we propose the following hypothesis.

Hypothesis 1: organizational virtuousness perception positively affects pro-social rule breaking.

\subsection{The Mediating Role of Psychological Empowerment}

Psychological empowerment is a comprehensive recognition of environment, resulted from individual's cognitive evaluation of such four aspects as his sense of meaning, competence, self-determination and impact. Those high with psychological empowerment will show flexibility at work and innovation for solving new problems [16]. Basing on the social information processing theory, we proposed that employees' perception of organizational virtuousness as an important social clue will affect their own psychological empowerment, which in turn affects pro-social rule breaking.

Firstly, Organizational virtuousness perception promotes the psychological empowerment of employees. Cameron believes that organizational virtuousness consists of two aspects: Features (such policy, culture or process) of encouraging virtuousness in the organization, and the virtuous behavior of individuals or groups in the organization [2]. In virtuous organization, employees will interpret the social information of these two aspects and construct meaning in cognition. On the one hand, virtuous organizations pursue social improvement and create social value beyond their own interests [5]. As for the organization's employees, virtuous organizations tend to pay attention to the development of human capital, giving priority to employee welfare [20], with its policy and culture often characterized by giving trust, compassion, forgiveness, virtue, etc., rather than merely focused on the economic benefits of employees' labor value. Employees 
will interpret these social information, perceive the organization's support and tolerance of their work, and feel less control from the organization, thus promoting psychological empowerment [21]. On the other hand, there will be more pro-social behaviors within the virtuous organization, resulting in more mutual assistance and cooperation [2]. When employees perceive help and support from their leaders or colleagues they will increase social exchange with key members of the organization, get the sense of power, and thereby promote their perception of self-determination and influence [22]. At the same time, mutual aid and cooperation working relationship will lead to more abundant resources and information sharing, can make the employees feel their control and influence about the work, and raise the consciousness of the work and impetus to problem-solving [23]. Previous studies also show that depending on each other and cooperation can enhance individual empowerment, helping networks within the organization is conducive to employees' empowerment experience [24], and supportive working relationship bears a positive correlation with psychological empowerment [25]. Thus, employees' awareness of organizational virtuousness indeed promotes their psychological empowerment.

In addition, Psychological empowerment promotes pro-social rule breaking among employees. First of all, the higher the psychological empowerment is, the greater intrinsic motivation for work there will be [26]. Driven by intrinsic motivation, employees will focus on how to get their work done [27], rather than blindly follow the inherent norms of organization. Hence, they are more likely to be against the rules of the organization in order to optimize the work efficiency. Meanwhile, due to pro-social rule breaking are challenging and risky by nature, only when there are enough confidence and resources to deal with the high-risk and pressure of such a behavior will the employees show the behavior. Employees of high psychological empowerment can perceive their own sense of control and influence at work; they have a certain autonomy and decision-making power; their ability to resort to surrounding resources and to take hold of matters accordingly increases; and they have the confidence and the ability to deviate from the organization rules so as to perform their duties. In an emergency or when necessary, they will be more aware of their work significance, they will attach vital importance to their work, and they will adopt innovative ways to solve the company's problems [28]. In addition, employees of high psychological empowerment tend to appreciate the opportunity given by their organization for independent decision-making, challenge-taking and responsibility-bearing [29], as a result of which they will feel more obliged to reward their organization and safeguard its benefits. The empirical research also manifests that psychological empowerment bears a positive correlation with such altruistic behaviors that challenge the status quo as change-oriented organizational citizenship behavior [30] and voice behavior [31]. Therefore, when faced with urgent decision-makings, employees with high psychological empowerment may be more willing and able to perform pro-social rule breaking. On the base of these arguments, this study proposes the following hypothesis. 
Hypothesis 2: psychological empowerment plays an intermediary role in the relationship between organizational virtuousness perception and pro-social rule breaking.

\subsection{The Moderated Role of Proactive Personality}

According to the theory of social information processing, the process of social information processing is affected by individual differences, and its follow-up behavior is also different [18]. Studies show that even if the outside world provides the condition for the pro-social rule breaking, the individual also will not necessarily show the pro-social rule breaking. Individual pro-social rule breaking are affected by the subordinate personality traits. Proactive personality refers to the personality tendency [19] that individuals take initiative to influence and change the environment. Based on this, we believe that proactive personality will moderate the relationship between psychological empowerment and pro-social rule breaking, and moderates the indirect effect of organizational psychological on pro-social rule breaking via empowerment.

In specific, employees of high proactive personality are better at spotting and seizing opportunities, and tend to take actions to make meaningful changes to the environment [32] [33]; they may be more concerned about improving their working efficiency and maintaining the organization's benefits. Besides, employees of high proactive personality have higher expectations for their own ability to change the environment, are more likely to work in a constructive way to deal with pressure [32], and they are more likely to treat the risky behaviors at work with a positive and optimistic attitude, and thus magnify the advantages of the risk-taking. Therefore, when faced with whether to risk breaking organization's rigid rules to optimize work efficiency and safeguard organization's benefits, employees of high proactive personality pay less attention to the unfavorable factors of pro-social irregularities than the choice opportunities stemmed from psychological empowerment, thus showcasing more pro-social rule breaking in order to achieve the purpose of its meaningful change to the environment. On the contrary, employees of low proactive personality tend to be more accommodating to the environment and lack the willingness to actively change the environment [32] [33], making it rather difficult to change the adverse environment or cope with work pressure [19], and their cognitive evaluation of pro-social rule breaking is relatively negative (such as being punished by the organization). Even if the environment provides conditions for engaging themselves in pro-social breaking, they may well not necessarily show any violation. Based on the aforementioned discussion, we propose the following hypothesis.

Hypothesis 3: proactive personality positively moderates the relationship between psychological empowerment and pro-social rule breaking.

Based on hypothesis 2 and hypothesis 3, we further propose that the mediating role of psychological empowerment in the relationship between organizational moral perception and pro-social behavior is subject to the moderating of proactive personality. Compared with employees of low proactive personality, 
employees of high proactive personality tend to have the initiative to change the environment, and have a more positive expectation about the results of risk-taking behaviors. When they interpret the psychological empowerment from organization's virtuousness clues, they tend to magnify the sense of control and the choice opportunities brought from mental freedom, and they will therefore take actions to make meaningful changes about their organization so as to improve the efficiency of the organization. In contrast, due to the lack of initiative to change the environment, employees of low proactive personality tend to focus on the negative results from disobeying organization's norms; even if they interpret the psychological empowerment from the organizational virtuousness, they tend to abide by organization's existing rules and regulations in order to avoid risks. Thus, we propose the following hypothesis.

Hypothesis 4: Proactive personality positively moderates the indirect effect of organizational virtuousness perception on pro-social rule breaking via psychological empowerment.

\section{The Framework for Research}

Based on the analysis of previous literature, we put forward the researching framework among organizational virtuousness perception, psychological empowerment, proactive personality and pro-social rule breaking. As showing in Figure 1, we put forward four hypothesizes, they are: 1) There will be a significantly positive correlation between organizational virtuousness perception and pro-social rule breaking. 2) Psychological empowerment mediated the relationship between organizational virtuousness perception and pro-social rule breaking. 3) Proactive personality positively moderates the relationship between psychological empowerment and pro-social rule breaking. 4) Proactive personality positively moderates the indirect effect of organizational virtuousness perception on pro-social rule breaking via psychological empowerment.

\section{Discussion}

This research extends and deepens previous research by developing and proposing a conceptual framework for investigating the sequentially mediating

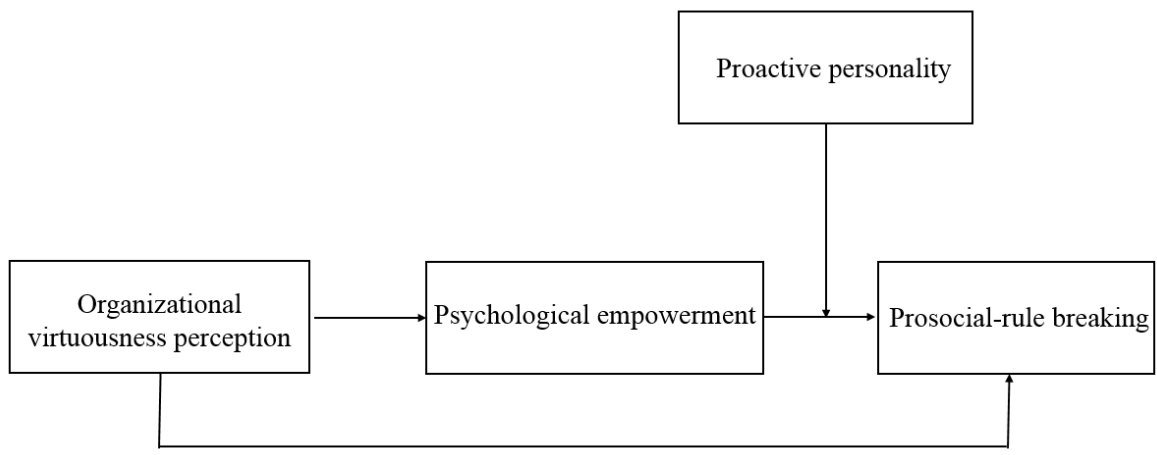

Figure 1. Conceptual model linking organizational virtuousness perception, psychological empowerment, proactive personality and pro-social rule breaking. 
process and moderating factor between organizational virtuousness perception and pro-social rule breaking. Specifically, this research contributes to the existing literatures in three ways. Firstly, going beyond previous researches which are majorly from emotional perspective, this study sheds light on cognitional mediating process between organizational virtuousness and work behavior. basing on social informational theory, this conceptual framework suggest that psychological empowerment, an integrated cognition including meaning, competence, self-determination and impact, may be triggered out through interpreting organizational virtuousness and subsequently influence pro-social rule breaking, which extend the researches in functional mechanism of organizational virtuousness. Second, through proposing that the impact of organizational virtuousness perception on pro-social rule breaking may depend on proactive personality, the framework also exploring the individual characters that may influence the effectiveness of organizational virtuousness perception in generating desirable work outcomes from an employee-environment interaction perspective, which extends the researches on the margin condition the effectiveness of organizational virtuousness. Third, the framework also introduces pro-social rule breaking as a favorable outcome of organizational virtuousness, which enriches literatures on outcomes of organizational virtuousness. Collectively, we believe that these research efforts are essential for advancing the knowledge development in the area of organizational virtuousness.

\section{Research Limitations and Further Research}

This study has several limitations that suggest avenues for additional research. First, the current research proposes a conceptual framework and offers propositions regarding the mediating process and moderating factor on the relationship between organizational virtuousness and pro-social rule breaking. Empirical testing is the next step in establishing the validity of our research framework and its propositions. Second, this research only identifies psychological empowerment as cognitive variable to explore the mediating process between organizational virtuousness perception and work outcomes. Other cognitive variable may be explored to further extend knowledge of currently proposed conceptual framework. Third, it may be fruitful in subsequent research to discuss other possible individual characters that may moderate the relationship between organizational virtuousness and work outcomes.

\section{References}

[1] Chun, R. (2005) Ethical Character and Virtue of Organizations: an Empirical Assessment and Strategic Implications. Journal of Business Ethics, 57, 269-284. https://doi.org/10.1007/s10551-004-6591-2

[2] Cameron, K.S., Bright, D. and Caza, A. (2004) Exploring the Relationships between Organizational Virtuousness and Performance. American Behavioral Scientist, 47, 766-790. https://doi.org/10.1177/0002764203260209

[3] Rego, A., Ribeiro, N. and Cunha, M.P. (2010) Perceptions of Organizational Vir- 
tuousness and Happiness as Predictors of Organizational Citizenship Behaviors. Journal of Business Ethics, 93, 215-235. https://doi.org/10.1007/s10551-009-0197-7

[4] Beadle, R., Sison, A.J.G. and Fontrodona, J. (2015) Introduction-Virtue and Virtuousness: When Will the Twain Ever Meet? Business Ethics: A European Review, 24, 67-77. https://doi.org/10.1111/beer.12098

[5] Cameron, K.S. and Winn, B. (2012) Virtuousness in Organizations. The Oxford Handbook of Positive Organizational Scholarship. Oxford University Press, New York.

[6] Moore, G. (2015) Corporate Character, Corporate Virtues. Business Ethics: A European Review, 24, 99-114. https://doi.org/10.1111/beer.12100

[7] Wright, T.A. and Goodstein, J. (2007) Character Is Not "Dead" in Management Research: a Review of Individual Character and Organizational-Level Virtue. Journal of Management Official Journal of the Southern Management Association, 33, 928-958.

[8] Tsachouridi, I. and Nikandrou, I. (2016) Organizational Virtuousness and Spontaneity: A Social Identity View. Personnel Review, 45, 1302-1322.

https://doi.org/10.1108/PR-09-2014-0192

[9] Hur, W.M., Shin, Y., Rhee, S.Y. and Kim, H. (2017) Organizational Virtuousness Perceptions and Task Crafting: The Mediating Roles of Organizational Identification and Work Engagement. Career Development International, 22, 12-31. https://doi.org/10.1108/CDI-11-2016-0192

[10] Mischel, W. and Shoda, Y. (1995) A Cognitive-Affective System Theory of Personality. Psychological Review, 102, 246-268.

[11] Salancik, G.R. and Pfeffer, J. (1978) A Social Information Processing Approach to Job Attitudes and Task Design. Administrative Science Quarterly, 23, 224. https://doi.org/10.2307/2392563

[12] Park, N. and Peterson, C. (2003) Virtues and Organizations. In: Cameron, K.S., Dutton, J.E. and Quinn, R.E., Eds., Positive Organizational Scholarship: Foundations of a New Discipline, Barrett-Koehler, San Francisco.

[13] Park, N., Peterson, C. and Seligman, M.E.P. (2004) Strengths of Character and Well-Being. Journal of Social and Clinical Psychology, 23, 603-619. https://doi.org/10.1521/jscp.23.5.603.50748

[14] Morrison, E.W. (2006) Doing the Job Well: An Investigation of Pro-Social Rule Breaking. Journal of Management, 32, 5-28. https://doi.org/10.1177/0149206305277790

[15] Thomas, K.W. and Velthouse, B.A. (1990) Cognitive Elements of Empowerment: An "Interpretive" Model of Intrinsic Task Motivation. Academy of Management Review, 15, 666-681.

[16] Frazier, M.L. and Fainshmidt, S. (2016) Voice Climate, Work Outcomes, and the Mediating Role of Psychological Empowerment a Multilevel Examination. Group \& Organization Management, 37, 691-715. https://doi.org/10.1177/1059601112463960

[17] Crick, N.R. and Dodge, K.A. (1994) A Review and Reformulation of Social Information-Processing Mechanisms in Children's Social Adjustment. Psychological Bulletin, 115, 74-101. https://doi.org/10.1037/0033-2909.115.1.74

[18] Vardaman, J.M., Gondo, M.B. and Allen, D.G. (2014) Ethical Climate and Pro-Social Rule Breaking in the Workplace. Human Resource Management Review, 24, 108-118. https://doi.org/10.1016/j.hrmr.2012.05.001

[19] Bateman, T.S. and Crant, J.M. (1993) The Proactive Component of Organizational 
Behavior: A Measure and Correlates. Journal of Organizational Behavior, 14, 103-118. https://doi.org/10.1002/job.4030140202

[20] Dahling, J.J., Chau, S.L., Mayer, D.M. and Gregory, J.B. (2012) Breaking Rules for the Right Reasons? An Investigation of Pro-Social Rule Breaking. Journal of Organizational Behavior, 33, 21-42. https://doi.org/10.1002/job.730

[21] Gittell, J.H., Cameron, K., Lim, S. and Rivas, V. (2006) Relationships, Layoffs, and Organizational Resilience. Journal of Applied Behavioral Science, 42, 300-328. https://doi.org/10.1177/0021886306286466

[22] Spreitzer, G.M. (1996) Social Structural Characteristics of Psychological Empowerment. Academy of Management Journal, 39, 483-504.

[23] Mishra, A.K. and Spreitzer, G.M. (1998) Explaining How Survivors Respond to Downsizing: The Roles of Trust, Empowerment, Justice, and Work Redesign. Academy of Management Review, 23, 567-588. https://doi.org/10.5465/amr.1998.926627

[24] Vogt, J.F. and Murrell, K.L. (1990) Empowerment in Organizations. University Associates, San Diego.

[25] Corsun, D.L. and Enz, C.A. (1999) Predicting Psychological Empowerment among Service Workers: The Effect of Support-Based Relationships. Human Relations, 52, 205-224. https://doi.org/10.1177/001872679905200202

[26] Schriesheim, C.A., Neider, L.L. and Scandura, T.A. (1998) Delegation and Leader-Member Exchange: Main Effects, Moderators, and Measurement Issues. Academy of Management Journal, 41, 298-318.

[27] Spreitzer, G.M. (1995) Psychological Empowerment in the Workplace: Dimensions, Measurement, and Validation. Academy of Management Journal, 38, 1442-1465.

[28] Shalley, C.E. and Gilson, L.L. (2004) What Leaders Need to Know: A Review of Social and Contextual Factors That Can Foster or Hinder Creativity. Leadership Quarterly, 15, 33-53. https://doi.org/10.1016/j.leaqua.2003.12.004

[29] Liden, R.C., Wayne, S.J. and Sparrowe, R.T. (2000) An Examination of the Mediating Role of Psychological Empowerment on the Relations between the Job, Interpersonal Relationships, and Work Outcomes. Journal of Applied Psychology, 85, 407-416. https://doi.org/10.1037/0021-9010.85.3.407

[30] Choi, J.N. (2007) Change-Oriented Organizational Citizenship Behavior: Effects of Work Environment Characteristics and Intervening Psychological Processes. Journal of Organizational Behavior, 28, 467-484. https://doi.org/10.1002/job.433

[31] Jeung, C.W. and Yoon, H.J. (2018) When Leadership Elicits Voice: Evidence for a Mediated Moderation Model. Journal of Management \& Organization, 24, 40-61. https://doi.org/10.1017/jmo.2017.42

[32] Seibert, S.E., Crant, J.M. and Kraimer, M.L. (1999) Proactive Personality and Career Success. Journal of Applied Psychology, 84, 416-427. https://doi.org/10.1037/0021-9010.84.3.416

[33] Zhang, Z., Wang, M. and Shi, J.Q. (2012) Leader-Follower Congruence in Proactive Personality and Work Outcomes: The Mediating Role of Leader-Member Exchange. Academy of Management Journal, 55, 111-130.

https://doi.org/10.5465/amj.2009.0865 